\title{
Case Study: The "Office of Real Soon Now" for Visualization
}

S.P. Uselton

This article was submitted to

IEEE Visualization 2002, Boston, MA, October 27 - November 1 , 2002

\section{March 27, 2002}

\section{U.S. Department of Energy}

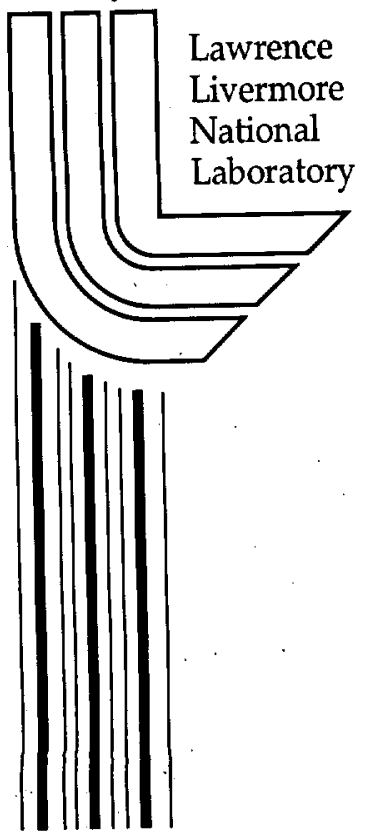




\section{DISCLAIMER}

This document was prepared as an account of work sponsored by an agency of the United States Government. Neither the United States Government nor the University of California nor any of their employees, makes any warranty, express or implied, or assumes any legal liability or responsibility for the accuracy, completeness, or usefulness of any information, apparatus, product, or process disclosed, or represents that its use would not infringe privately owned rights. Reference herein to any specific commercial product, process, or service by trade name, trademark, manufacturer, or otherwise, does not necessarily constitute or imply its endorsement, recommendation, or favoring by the United States Government or the University of California. The views and opinions of authors expressed herein do not necessarily state or reflect those of the United States Government or the University of California, and shall not be used for advertising or product endorsement purposes.

This is a preprint of a paper intended for publication in a journal or proceedings. Since changes may be made before publication, this preprint is made available with the understanding that it will not be cited or reproduced without the permission of the author.

This report has been reproduced directly from the best available copy.

Available electronically at http://www.doe.gov/bridge

Available for a processing fee to U.S. Department of Energy and its contractors in paper from

U.S. Department of Energy

Office of Scientific and Technical Information

P.O. Box 62

Oak Ridge, TN 37831-0062

Telephone: (865) 576-8401

Facsimile: (865) 576-5728

E-mail: reports@adonis.osti.gov

Available for the sale to the public from

U.S. Department of Commerce

National Technical Information Service

5285 Port Royal Road

Springfield, VA 22161

Telephone: (800) 553-6847

Facsimile: (703) 605-6900

E-mail: orders@ntis.fedworld.gov

Online ordering: http://www.ntis.gov/ordering.htm

OR

Lawrence Livermore National Laboratory

Technical Information Department's Digital Library

http://www.llnl.gov/tid/Library.html 


\title{
Case Study: The "Office of Real Soon Now" for Visualization
}

\author{
Samuel P. Uselton \\ Center for Applied Scientific Computing \\ Lawrence Livermore National Laboratory
}

\section{Introduction}

A variation on the "Office of Real Soon Now" has been designed and deployed at Lawrence Livermore National Laboratory (LLNL). The ASCI VIEWS (VIEWS) program [1], the element of the ASCI program developing tools for data management and visualization, is investigating a variety of display technologies, motivated in part by the large size, high resolution, and complexity of data sets that ASCI users frequently explore and analyze. While large, tiled displays have been well received at LLNL, availability and ease-of-use problems have motivated exploration of alternatives [2]. The "Office of Real Soon Now" Project $[3,4,5]$ at the University of North Carolina at Chapel Hill (UNC) has built "low fidelity" versions of the "Office of the Future" $[6,7]$ that can be installed in users' offices now.

At UNC, the Office of Real Soon Now installations use only a small number of relatively inexpensive projectors, generally two or three, that limit resolution and features. These projectors are connected to Microsoft Windows PCs or Apple computers that are used for daily activities, such as reading email, writing papers, and debugging programs. Even though the UNC faculty involved are predominantly computer graphics researchers, these display systems are used mainly for text-oriented applications [5] Designing, developing, and deploying an office-based system at LLNL would provide opportunities to adapt the system to our specific uses and to evaluate such systems for a range of tasks beyond those typically found at UNC. The goals of the LLNL display system are to exceed previous UNC versions in resolution, to run Unix-based applications, and to support interactive visualization of simulation data better than can be done via current workstations and monitors.

\section{Alternatives Considered: Design and Implementation}

The initial design of our display system had projectors placed in a 2-by-2 array in order to get the highest possible resolution using reasonably priced projectors. But because an office display system should run on a single, user-class workstation, we had difficulty finding a host supporting hardware-accelerated 3D graphics across four outputs. In the spring of 2001, Sun Microsystems demonstrated a system that supported four graphics cards used as a single display with hardware-accelerated Java3D graphics instructions. The system required an Ultra 60 workstation, which is substantially more than the typical Ultra 10 office workstation, but it seemed a viable possibility. The projector geometry was also difficult. For the best image quality, the projectors need to be arranged as far apart as the centers of their images. Reducing the spacing between projectors without reducing the image size means that the projectors are not projecting orthogonal to the screen. The result is a "keystone" distortion of the image in which the farther edge of the image is larger, distorting the rectangle into a trapezoid. Image keystoning also exacerbates the alignment difficulties, since adjacent edges may no longer be parallel. Another geometric difficulty is that the four pyramids of light from the projectors make it difficult to find a place for users to sit without casting shadows onto the screen.

Then, three companies announced $1280 \times 1024$ pixel resolution projectors that were substantially smaller, lighter, quieter, cooler, brighter, and less expensive than any previously available. Two such projectors have about $80 \%$ of the pixels of the four commodity projectors previously identified; such a system would provide a combined resolution of $2560 \times 1024$ pixels. These projectors can also be driven from a PC graphics card with two video outputs including 3D support. To preserve the largest possible pixel count and to avoid complexities in blending overlapped images, abutting images were selected. 


\section{Systems as Implemented}

Two systems were installed in two separate offices in order to provide better feedback. The components used in each office are listed in Table 1. The projectors were hung upside down (allowing the off-center projection to reduce keystone problems) from an Opti Trilite truss by projector-mounting hardware from Chief Manufacturing (see Figure 1). The twelve-inch, triangular truss was used to allow enough clearance for the projectors. The truss was bolted to the wall a little more than seven feet above the floor. One sheet of GatorFoam, 4 feet by $8 \mathrm{feet}$, was used as the projection screen in each office, as shown in Figure 2.

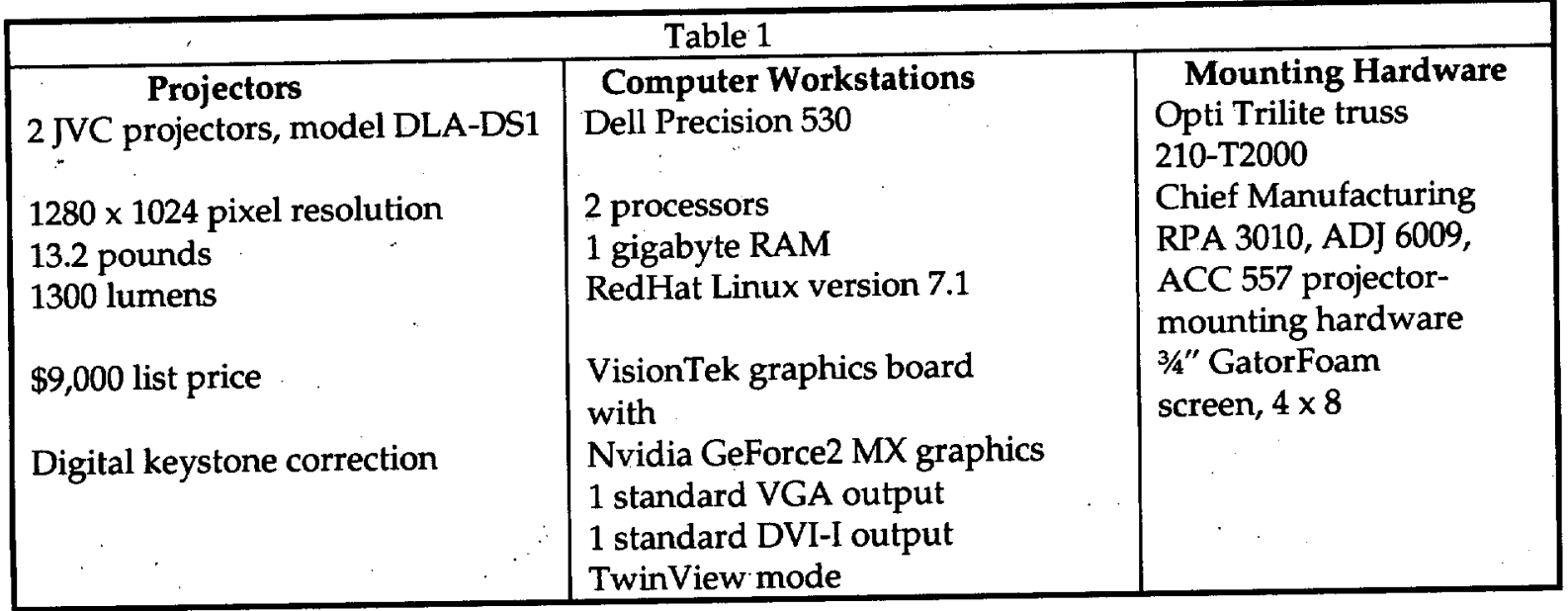

While the components of the systems are identical, installation details varied for each office. In the first installation, the truss and projectors were mounted on an interior wall and the projection screen propped up on the desk against the opposite wall. During the installation, the user, Gary Kerbel, gave feedback that he strongly preferred the images to be as bright as possible. The image size was reduced from 96 by 36 inches to 80 by 30 inches, since the same energy in a smaller area produces a brighter image.

Gary works while seated in a unique chair that gives him a partially reclining posture. This unusual seating requires that he have a fairly high display, so the top of the screen is much further from him than the bottom, particularly if the screen is absolutely vertical. He sits fairly close to the screen, which increases the importance of the screen angle. UNC recommends tilting the screen to make it more perpendicular to the projectors; in their experience, using keystone correction affects image quality. However, in this situation the user preferred to tilt the screen in the opposite direction, making it more perpendicular to his view, and therefore more oblique to the projection direction. The keystone correction provided by the projectors is used at its maximum setting. To complete the picture, he usually works with the lights off and the blinds partially deployed so that image contrast is improved (see Figure 3).

Our second volunteer, Milo Dorr, has a more rectangular office, with windows on two sides. His truss is mounted above the windows on an exterior wall, as seen in Figure 4. Milo sits conventionally and asked to have the large display as low and as vertical as possible. He also said he would prefer brighter images, so we adjusted the image size to be small. He tried working with the lights out but finds he has less eye fatigue at days end if he has more ambient light, so he typically works with half of his lights on. After initial experimentation, the screens in both offices were trimmed to 3 feet by 7 feet, given rounded corners, and mounted using velcro. 


\section{User Experience}

After a few weeks of use, each user was informally interviewed to get preliminary assessments of these display systems. Both users liked the increase in the amount of information that can be displayed at once. They both commented on how the large format was especially valuable for use by small groups. Wireless keyboards and pointers had been added and were not only convenient for the users but also facilitated sharing control during collaboration sessions. There were little or no problems associated with shadows blocking the front-facing projectors. The projector heat and fan noise was noticeable, but not objectionable. Both users would like the images to be brighter, higher contrast, and higher resolution. Both users noted color differences between the two projectors and often placed window boundaries along the color discontinuity to minimize this distraction.

Gary, whose projectors were mounted on an interior wall, commented on vibrations resulting from things like doors closing down the hall. He also said that it was difficult to get the two images to stay precisely aligned, but that he found the usual one-sixteenth of an inch mismatch acceptable. We installed panels called "flags" in Gary's office to address a brighter area in the center, where light from the projectors "leaking around the images" overlapped each other's image. The flags reduced the area and softened the edges but did not totally eliminate this bright area. Gary said he has used the display primarily for textoriented work, although he did display some images as part of the process of getting visualization software he uses to run under this version of Linux. This usage was not enough to provide much feedback, but he expects to be doing much more work with visualization and images soon. In spite of some of the problems, Gary is very enthusiastic about using the system.

Milo's overall assessment was more cautious than Gary's. He has used the system for visualization, but primarily 2D, and with relatively low interaction demands. He likes the large format but is uncertain how much difference it makes in his analysis. Milo observed intermittent increases and decreases of brightness, across a projector's image, which he finds distracting. These changes happen on either projector, are relatively uniform across one projector's image, and can stay brighter for time periods from fractions of a second to several seconds. About three weeks after the interviews, Gary began experiencing the same intermittent intensity variation.

\section{Conclusions \& Recommendations}

The projector-based display systems installed at LLNL use higher resolution projectors than any in office use at UNC. Our users sit closer to the screens, so the image subtends a larger view angle than the monitor it replaces. We have not been as meticulous in positioning the screens perpendicular to the center of projection; we chose to orient them for the users' best view and use the projector's features to correct the image distortion. Our new model, higher resolution projectors accomplish this correction better than expected. The projectors are bright enough for a darkened room, but the images lose contrast when ambient light is present. Color matching between projectors and color consistency across a single image could be better. Mounting our projectors on the wall means they are lower than UNC's original arrangement, so the angle to correct is not as large. The truss system was easy to install and works quite well to provide flexibility in spacing the projectors precisely for a chosen image size. Mounting it on a structural wall results in less vibration than when mounted on an interior wall.

The conversion from Unix to Linux workstations was not an issue. Feedback is that these machines are faster and have more memory than the workstations replaced. Issues with the graphics cards include limited bandwidth of the analog signal from the DVI-I output and a substantial difference between that signal and the signal from the other output. A noticeable color difference between the output channels may be due to the projectors, the graphics cards, or both. Both image brightness and projector heat should be checked during the summer. Longer usage will also give more information on maintenance and 
system stability. Even though the systems are not perfect, preliminary user reaction is generally positive. Additional experience, particularly with image-oriented applications, is needed. These projectors are substantially more expensive than monitors, but prices continue to drop rapidly while resolution and features improve. Reaction by the users seems sufficiently positive to continue the evaluation and include projectors in the list of possibilities for advanced office displays. Higher resolution projectors are preferable to attempting multiple rows of projectors in an office. A more complete description can be found in a technical report [8].

As with most projects, many people have contributed to these results. The ASCI VIEWS program funded this project. Several people from UNC were very helpful, particularly Herman Towles, Greg Welch, Henry Fuchs, and Gary Bishop. At LLNL, too many to name here provided a variety of assistance, but the most important contributors are Milo Dorr and Gary Kerbel, who agreed to try these systems and have been ideal early adopters.

\section{References}

[1] Herman, P.D. "First-Generation ASCI Production Visualization Environment," IEEE Computer Graphics \& Applications, vol 19, no 5, 1999, pp 66-71.

[2] Schikore, D.S., R.A. Fischer, R. Frank, R. Gaunt, J. Hobson, and B. Whitlock, "High-Resolution Multiprojector Display Walls," IEEE Computer Graphics \& Applications, vol 20, no 4, 2000, pp 38-44.

[3] Gary Bishop's Office of Real Soon Now: http://www.cs.unc.edu/ gb/office.htm

[4] Greg Welch's Office of Real Soon Now: http://www.cs.unc.edu/ welch/oorsn.html

[5] Bishop, Gary, and Greg Welch, "Working in the Office of 'Real Soon Now'”, IEEE Computer Graphics and Applications, July/August 2000: 76-78.

[6] Raskar, Ramesh, Greg Welch, Matt Cutts, Adam Lake, Lev Stesin, and Henry Fuchs, "The Office of the Future: A Unified Approach to Image-Based Modeling and Spatially Immersive Displays", Computer Graphics. M. F. Cohen. Orlando, FL, USA (July 19 - 24, 1998), ACM Press, Addison-Wesley: 179-188.

[7] The Office of the Future Project: http://www.cs.unc.edu/ raskar/Office/

[8] Uselton, Samuel P., "The 'Office of Real Soon Now' Western Pilot: Projectors in Offices," Lawrence Livermore National Laboratory, UCRL-ID-147597, March 2002.

This work was performed under the auspices of the U. S. Department of Energy by the University of California, Lawrence Livermore National Laboratory under Contract No. W-7405-Eng-48. 


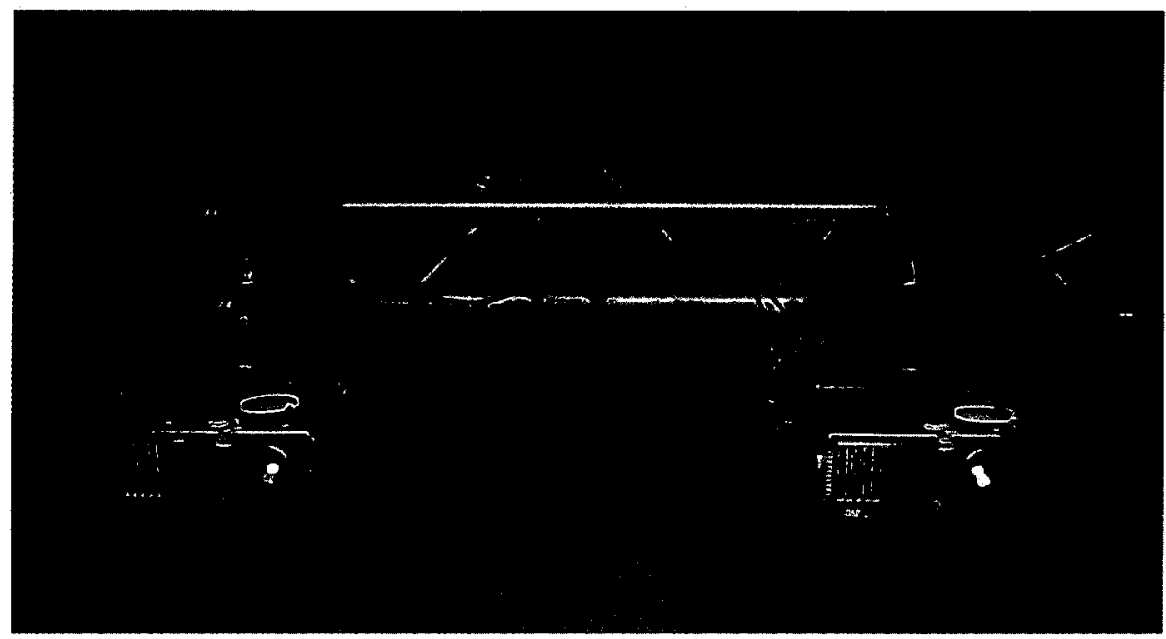

Figure 1. Two projectors suspended from an Opti truss by Chief Manufacturing mounting hardware.

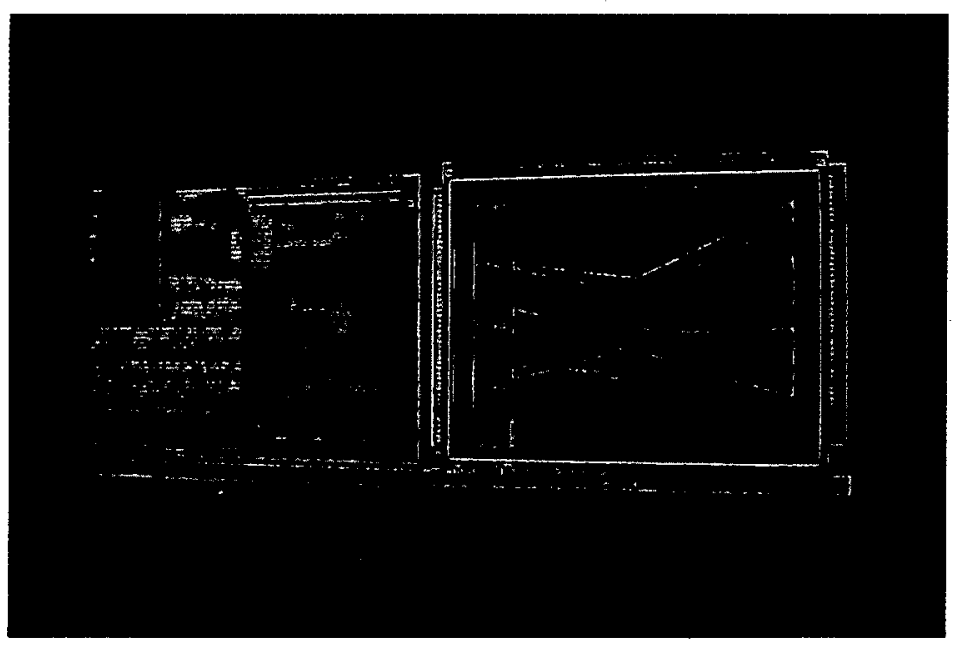

Figure 2. A GatorFoam screen with images from two projectors (before trimming and mounting).

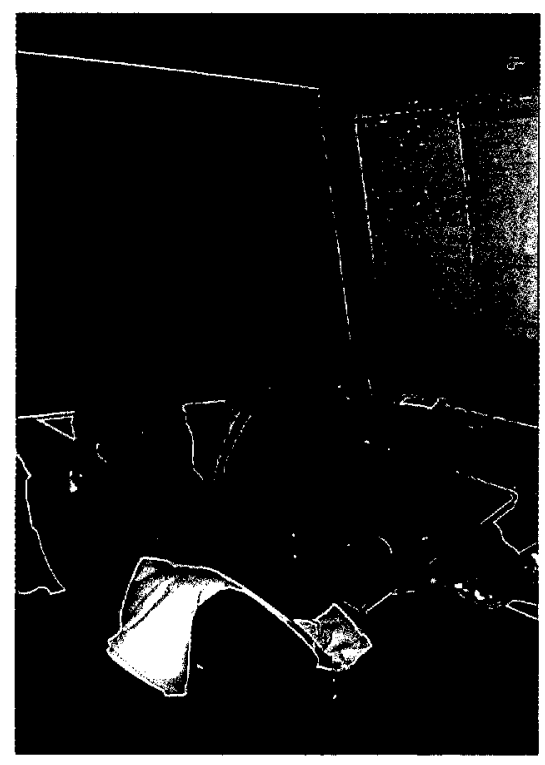

Figure 3. Gary Kerbel's work environment.

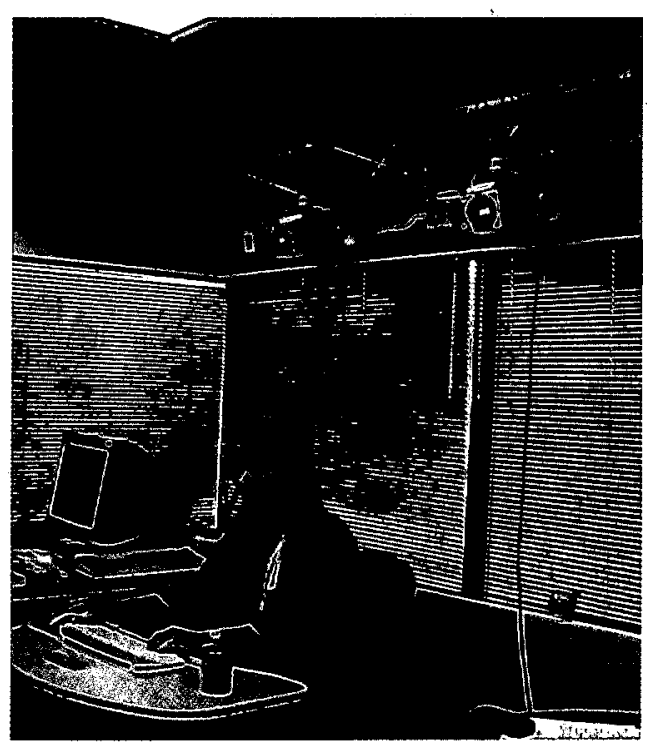

Figure 4. Milo Dorr's work environment. 